\title{
Risk elements in quality management for manufacturing enterprise
}

\author{
Elementy ryzyka w zarządzaniu jakością \\ w przedsiębiorstwie produkcyjnym
}

\section{MAŁGORZATA KOZAKIEWICZ GRZEGORZ SAWICKI *}

\author{
Discussed are chosen risk aspects in quality \\ management system. Presented is a model of \\ production process. The Fishbone Diagram was \\ developed. Possible approach to planning actions to \\ address risks and opportunities indicated. \\ KEYWORDS: quality management, risk, Fishbone \\ Diagram
}

Running a production business involves the constant need to anticipate the risks that affect the production process and the opportunities for the company's development. Due to the dynamically changing needs of enterprises in the revised standard PN-EN ISO 9001:2015, attention is paid to the integration in business activities of quality management system (QMS) processes with business processes taking into account risk-based thinking [3]. The process advisor recommends the implementation of the identification of risk factors and opportunities relevant for the proper functioning of the company. The QMS aims to achieve the intended goals, strengthen the desired effects, and prevent or reduce these undesirable and constantly improving businesses. It is therefore extremely important to include risk elements in a manufacturing enterprise by identifying hazards and assessing their impact on the quality of the final product.

\section{Risk analysis in the quality management system}

Risk analysis in the QMS of the enterprise should be a source of information on activities aimed at developing the organization without interruption, maintaining production continuity and meeting customer requirements and developing product competitiveness on the market. The standard PN-EN ISO 9001:2015 does not imply a method of conducting analysis and risk assessment. The risk may be related to the individual processes occurring at the time of production, as well as to plans, ventures, closer and further surroundings, and changes in the organization. On the basis of the information obtained, it is necessary to plan and take action on the identified risks and opportunities.

The algorithm proposed in PN-ISO 31000:2012 [4] can be used for risk assessment, i.e. analysis and risk evaluation.

\footnotetext{
* Inż. Małgorzata Kozakiewicz (mal.kozakiewicz@gmail.com), dr inż. Grzegorz Sawicki (grzegorz.sawicki@wat.edu.pl) Wojskowa Akademia Techniczna
}

DOI: https://doi.org/10.17814/mechanik.2017.7.93

You can use one of the most appropriate approaches for estimating the likelihood of any undesired event that has been identified as a threat. The data used may be from expert or retrospective or be calculated on the basis of the frequency of events using analytical or simulation techniques. Based on the results of the risk assessment it is possible to control it. During estimation, risk level measures are created to classify it. Risk levels are assigned to groups of eligibility in terms of, for example, socio-economic aspects or environmental impacts. The results of the analysis may be used by the decisionmaker to assess the acceptable level of risk and to assist in choosing between measures to reduce or avoid potential risks.

It is important to eliminate hazards or reduce the likelihood or consequences of their occurrence. The critical element of a system's security function is the identification of the threat, and therefore the proper understanding and understanding of its importance for the operation of the system. Threat analysis is performed to identify hazards, their effects, and their causes. Risk analysis is used to understand the risks involved in a given process. This allows us to determine the severity of the threat and to establish measures to eliminate or mitigate identified threats. To effectively analyze threats, you need to understand what they involve, how they can be identified and defined [1]. It is important to understand the nature of the threat, its impact on the process under consideration. During the analysis, it is necessary to first understand the nature of the threat. Threats are predictable, and if something can be predicted, it can also be eliminated or controlled.

\section{Model of quality management system}

It is important to understand and define how the individual elements of an organization affect one another in order to ensure the effective functioning of the company. This will help identify the processes in the enterprise, manage them and their interrelations. This approach makes it possible to achieve goals effectively because resources and activities are treated and managed as a process [3]. Within each process, the input data is transformed into output. The basic input data in the production company are raw materials, commercial information, financial resources, people and machines. In turn, the output is a final product, the main purpose of the business process. The input and output data should be monitored by defining their structure, relationships and implementing monitoring methods. 
The execution of the process consists in performing the daily duties of the employees, and each order is an impulse that triggers a series of activities completed by the delivery of the final product to the customer. They also include the preparation of the price offer and the terms of order fulfillment, their approval and execution of the product and processes such as production planning, human resources management, finance, administration, procurement. In addition, they include quality controls, corrective actions and the identification of risk factors and opportunities at each stage of the process.

To identify processes, you must specify their order and their relationship. Exemplary relations between processes in a manufacturing enterprise are shown in fig. 1.

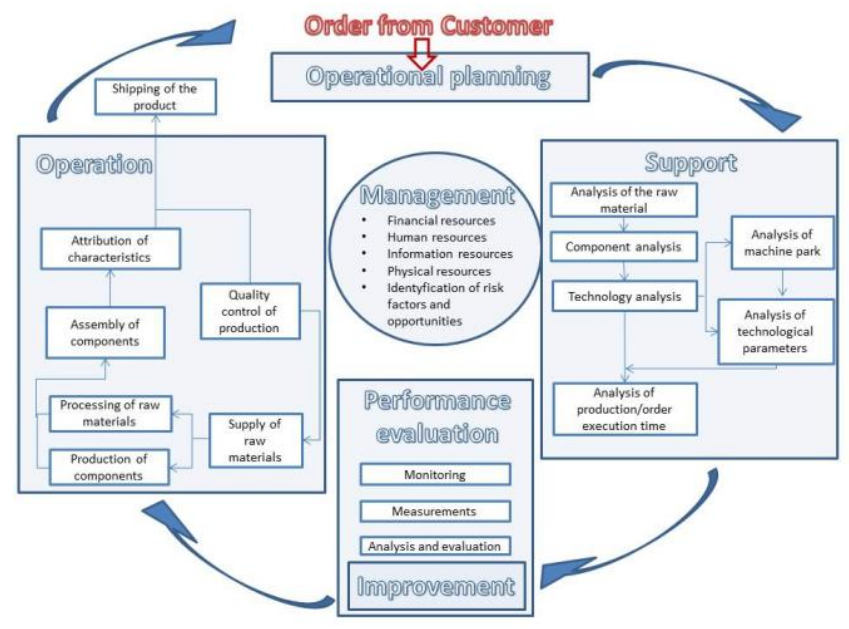

Fig. 1. Production process diagram

Defining the purpose and direction of action and creating conditions for the functioning of the company are the primary responsibility of the top management. The result of these activities is to provide the material, financial and personnel resources needed to carry out the tasks entrusted. They allow the involvement of competent personnel in process activities. Product realization takes place by using the accumulated resources and configuring them according to customer requirements. The result of the production cycle is the final product. Processes at each stage require constant analysis of the risks and opportunities associated with their implementation. The results of the activities are monitored, analyzed and evaluated. On this basis, it is possible to continuously improve the company.

The functioning of the company is influenced by both the organizational environment and the interested parties involved. The key interested parties in the organization are the customers, partners, suppliers, legal and regulatory body, the competition, the local community, the employees and the owners. They are both sources of opportunities and risks. They should be taken into account in identifying the risks and development opportunities of the organization, planning activities related to risks and opportunities, and then implementing the QMS activities [3].

It is proposed to adopt a two-stage model to characterize the proximity and further businesses (fig. 2). External factors, occurring in the distant environment, the organization has limited impact. On the one hand, they represent opportunities and opportunities and, on the other, they may be sources of requirements and constraints. Neighborhood - including staff, technical equipment, know-how resulting from research and development, knowledge of the organization, marketing techniques - creates internal factors to which the company directly interacts. They are the strategic resources your organization uses to achieve your business goals.

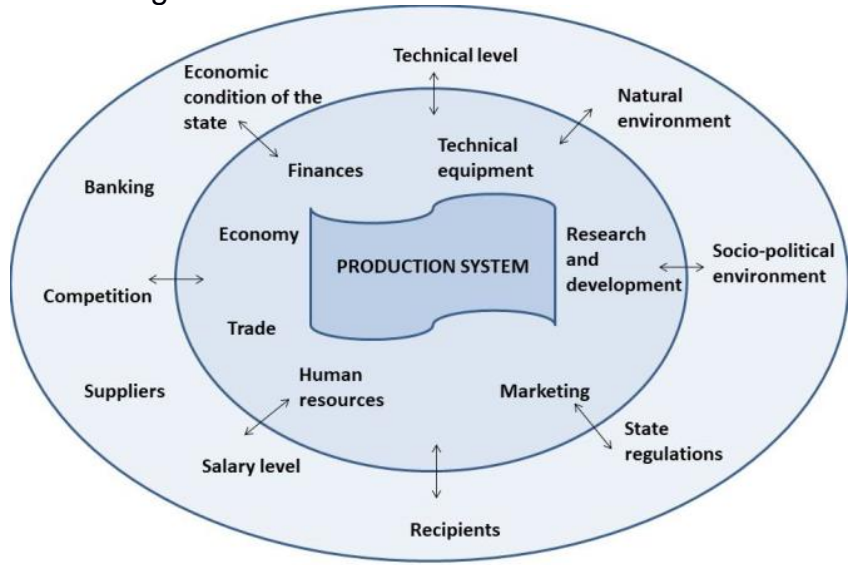

Fig. 2. Model of production process in two-stage environment

The challenge - in line with PN-EN ISO 9001:2015 standards - which organizations are currently in, is to incorporate the business environment, relevant interested parties and requirements into the business environment, and to plan activities that relate to the risks and opportunities that arise. It may be helpful to use one of the basic tools supporting quality management cause and effect diagram [2]. The analysis focused on the nearer environment and the production system under which the processes covered by the QMS are being implemented.

\section{Cause and effect diagram}

Effective activities to meet the quality requirements of the product include effective identification and problem solving during production. Problem solving is the definition of their origin, often the result of the accumulation of many events, not always of unambiguous nature. Defining problems that interfere with achieving the quality of the final product allows you to understand the conditions that generate the problem and to formulate hypotheses about the cause of the problem. Detecting and eliminating quality problems in production is a major aspect of corrective action taken after discrepancies have been identified, e.g. as a result of quality control of the production process.

In solving these problems, you can use the cause and effect diagram (Ishikawa diagram) [2]. "Brainstorming" will help brainstorming with selected specialists in the interdisciplinary team. Obtained results are usually presented in graphical form. An example of such an analysis is the Ishikawa diagram for the production process shown in fig. 3. Of course, it can be further developed by identifying the causes of problems on subsequent levels. Expansion and detail depend on the limits and assumptions adopted before the analysis begins.

As the scope of the diagram is extended to ensure its legibility, the factors that affect the product's non- 
fulfillment are described in the points categorized in the relevant category of causes.

\section{Category: MAN}

1. Inadequate performance:
1a) Fatigue
1b) Routine
1c) Monotony
1d) Bad motivation system
1e) No experience
2. Problems in cooperation:

2a) Internal conflicts

2b) No sharing of responsibilities

3. Incorrect operation of the machine / Incorrect installation:

3a) No experience:

3a.1) Short work experience

3b) No knowledge:

3b.1) No training

3b.2) Incorrect information flow

3b.3) No instructions

3b.4) Unclear procedures

\section{Category: MACHINE}

4. Frequent downtime:

4a) Non-systematic machine maintenance

4b) Obsolete machines:

4b.1) No investment

4c) Beginning of exploitation ("lapping") of new machines

5. Incorrect operating parameters of the machine:

5a) Incorrectly designed technological process

5b) Inadequate operating range

5c) Incorrect operation of the machine: see point 3

\section{Category: MATERIAL}

6. Improper quality of raw material

7. Delivery delay

8. Incompatible components / Incompatible parameters

9. Inadequate material

10. Incorrect number of subassemblies

\section{Category: METHOD}

11. Inappropriate packaging method

12. Inadequate mounting method

13. Inappropriate method of processing raw material

14. A large number of manual operations

15. Invalid work organization

16. Sporadic quality checks

\section{Category: MANAGEMENT}

17. No investment

18. Lack of long-term and short-term planning

19. No motivation system

20. Little innovation:

20a) Fear of change

21. Improper flow of information

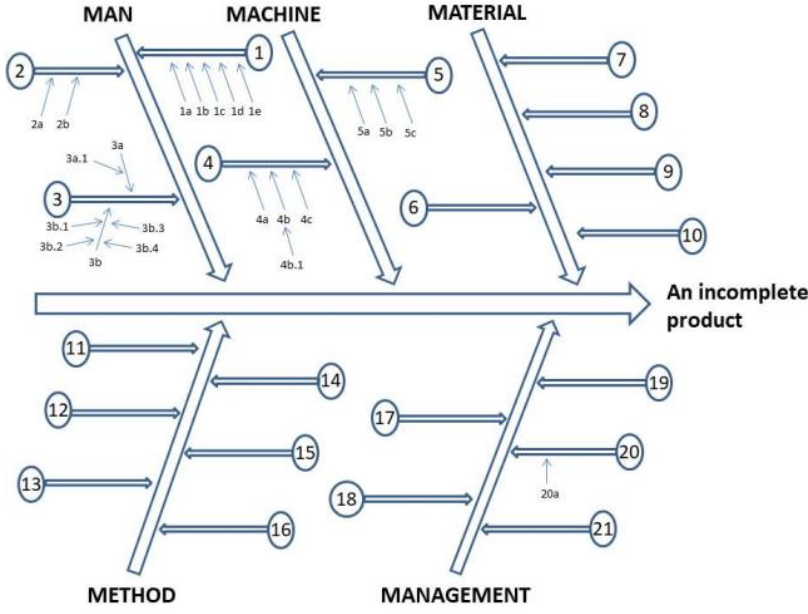

Fig. 3. Cause and effect diagram for the production process

The analysis of the Ishikawa diagram allows to rank the factors that influence the production of an incorrect product. The identified causes and indications indicate the direction of action taken to improve the quality of production. The basis is to identify risks and risks that come from different areas of the company - "categories". Depending on how the diagram is analyzed, you can get an answer to the question, "Why is the problem in production?" Or "What effect does the problem have?". The results of the causal analysis enable not only the identification of direct errors. They also show indirect problems resulting from, for example, improper management or flow of information between processes or lack of feedback.

The main advantage of the analysis using the Ishikawa diagram is the objective diagnosis of production and organizational problems in the enterprise. Classification and hierarchy of the causes of the problem make it possible to make changes that correct errors and the effects of badly functioning system components. In addition, the results of the analysis provide an important source of information for further investigation of problems in the QMS and their causes.

\section{Conclusions}

The concept of risk in the production process is used in the context of managing the risks associated with taking measures limiting its occurrence and hindering possible consequences. Characterized risk analysis allows identification, classification, measurement and identification of response methods.

Properly applied process approach allows systematic development of the company and increase the quality of its products, naturally taking into account the closer and further environment. Risk planning in QMS need not be complicated and expensive. The results of causal analysis conducted by an interdisciplinary team made up of staff of the organization, or with the support of an external facilitator, can be used.

An example of causal analysis is presented in the basic form. Full analysis needs to be detailed in terms of production methods, product characteristics and the nature of the organization. The Ishikawa diagram allows you to identify and prioritize problems. Thorough analysis of the diagram and its analysis is the primary way of revealing production errors that reduce the quality of the final product. Detects the direct causes of an undesired 
event and identifies indirect factors, i.e., location in the organization requiring improvement.

The proposed approach enables to identify risks related to the environment of the production process. Selection of factors from different categories (fig. 3) will be the basis for planning and implementing QMS activities and will help to meet one of the main requirements of PN-EN ISO 9001:2015 for risk and opportunity activities.

\section{REFERENCES}

1. Ericson A.C. "Hazard Analysis Techniques for System Safety". New Jersey: Wiley-Interscience, 2005.

2. Hamrol A. "Zarządzanie jakością z przykładami". Warszawa: PWN, 2008.

3. PN-EN ISO 9001:2015 - Systemy zarządzania jakością Wymagania.

4. PN-ISO 31000:2012 - Zarządzanie ryzykiem - Zasady i wytyczne. 